\title{
Satisfaction towards Skilled Delivery Services and Associated Factors among Mothers who Gave Birth at Government Health Facilities, Jimma Town, Ethiopia
}

\author{
Alemayehu Gonie $^{1^{*}}$, Bosena Tebeje ${ }^{2}$, and Makeda Sinaga ${ }^{2}$
}

${ }^{1}$ Department of Nursing, College of Health Sciences, Debre Berhan University, Debre Berhan, Ethiopia

2Department of Nursing, College of Public Health and Medical Sciences, Jimma University, Jimma, Ethiopia

*Corresponding author: Gonie A, Department of Nursing, College of Health Sciences, Debre Berhan University, Debre Berhan, Ethiopia, Tel: +251912379531; E-mail: alemayehugonie19@gmail.com

Received date: September 18, 2018; Accepted date: September 27, 2018; Published date: October 02, 2018

Copyright: $@ 2018$ Gonie A, et al. This is an open-access article distributed under the terms of the Creative Commons Attribution License, which permits unrestricted use, distribution, and reproduction in any medium, provided the original author and source are credited.

\begin{abstract}
Background: Client satisfaction is patients' subjective responses to experienced care mediated by personal preferences and expectations. Allowing women to express their views about different phases of delivery service, the care provided by different health professionals provides richer information about the care they received. However, limited studies are available that assess mothers' satisfaction towards skilled delivery service in Jimma town government health facilities. So, the purpose of this study was to assess satisfaction on skilled delivery service and associated factors among mothers who delivered at Jimma town government health facilities.
\end{abstract}

Methods: A cross-sectional study involving both qualitative and quantitative methods of data collection was used from March 5-May 10/2014. A total of 366 mothers were enrolled in the study using interviewer-administered structured questionnaires. In-depth interview was conducted for qualitative data. Data were analyzed using SPSS version 20.0. Logistic regression analysis was applied. The independent variables with $p<0.05$ in multiple analysis were considered as predictors of delivery service satisfaction. Qualitative data were thematically analyzed.

Results: In this study, $78.7 \%$ of mothers were satisfied with delivery services. Mothers who had planned delivery were 2.5 times more likely to be satisfied than those referral delivery cases (AOR 2.5 and $95 \% \mathrm{Cl}=1.2-5.6$ ) and mothers who obtained free delivery services were 2.9 times more likely to be satisfied than mothers who paid (AOR=2.9 and $95 \% \mathrm{Cl}=1.3-6.4$ ). Mothers who perceived the toilet was cleaned were 2 times more likely to be satisfied than their counterparts $(\mathrm{AOR}=2.0$ and $95 \% \mathrm{Cl}=1.01-3.8)$ and mothers who felt being treated with respect were 1.7 times more likely to be satisfied than mothers who did not feel respected ( $A O R=1.7$ and $95 \% \mathrm{Cl}=1.1-6.8$ ) and mothers who perceived their privacy was maintained were 1.5 times more likely to be satisfied than their counterparts $(\mathrm{AOR}=1.5$ and $95 \% \mathrm{Cl}=1.9-9.5)$.

Conclusion: In general, more than three-fourth of mothers were satisfied with skilled delivery services. This study also revealed predictors of delivery service satisfaction: planned delivery, free delivery service, perceived cleanness of toilets, and perceived presence of privacy and empathetic interactions of staffs. As a recommendation, those health facilities should take into account mothers' feedback to improve the quality of delivery service.

Keywords: Skilled delivery service; Mother's satisfaction; Jimma town health facilities

Abbreviations ANC: Antenatal Care; AOR: Adjusted Odds Ratios; CI: Confidence Interval; COR: Crude Odds Ratios; HC: Health Center; JUSH: Jimma University Specialized Hospital; MDG: Millennium Development Goal; MMR: Maternal Mortality Ratio; OR: Odds Ratios; WHO: World Health Organization

\section{Background}

Globally, there were an estimated 289000 maternal deaths in 2013. Sub-Saharan Africa region contributed $62 \%$ of those maternal deaths. Global maternal mortality ratio (MMR) in 2013 was 210 maternal deaths per 100000 live births. MMR in developing regions (230 deaths per 100000 live births) was 14 times higher than in developed regions
(16 deaths per 100000 live births). Sub-Saharan Africa has the highest regional MMR (510 deaths per 100000 live births) [1].

In Ethiopia, MMR was estimated to be 420 per 100,000 live births in 2013 [1]. In other words, for every 1,000 live births about four women died during pregnancy, childbirth or within two months of childbirth. It has been shown that maternal mortality partially is attributed to unsatisfied institutional delivery experience which in turn leads to home delivery [2]. Traditionally, the quality of health care services was assessed from the provider's point of view or based on certain outcomes determined by the assessor, with no input from clients accessing the services. Over time, clients' perception of quality of healthcare services was being seen as an important measure in examining the quality of health care [3]. Patient satisfaction, as outcomes of healthcare services, has been emphasized as measures of quality healthcare services from the patient's perspective [4]. Donabedian (1988), the leading theorist in the area of quality assurance, postulated that client satisfaction may be considered to be 
one of the desired outcomes of care, even an element in health status itself. He defined patient satisfaction or dissatisfaction as the patient's judgment on the quality of care in all its aspects, particularly interpersonal process. He emphasized that client satisfaction is a measure of the quality of care because it gives information on the provider's success at meeting those client values and expectations [5].

Allowing women to express their views about different phases of delivery service, the care provided by different health professionals provides richer information about the care they received. Their own words provide a more realistic picture of the care they received [6]. Therefore, determining and knowing women's satisfaction with delivery service helps in avoiding barriers to women's satisfaction and enables to generate changes in health-seeking behavior [7].

The government of Ethiopia was committed in achieving MDG-5 to improve maternal health with a target of reducing maternal mortality ratio by three-quarters over the period 1990 to 2015. Accordingly, the federal ministry of health has applied multi-pronged approaches to reduce maternal mortality [8]. These approaches were improving access to and strengthening facility-based maternal and newborn services by implementing basic emergency obstetric care and improving referral systems [9]. Despite the notable achievements of these initiatives, only eleven percent of births were assisted by skilled attendance in 2013 [10]. Less than $1 \%$ of births were assisted by health extension workers and $57 \%$ of births were assisted by relatives. Twentyeight percent of births were assisted by traditional birth attendant while 4 percent of births were unattended which was very far from the MDG target of $90 \%$ coverage [8].

Reasons given by researchers for low skilled birth attendance include; poor quality of maternal healthcare services, women's unhappy previous experience of institutional delivery service/don't trust health facility, disrespectful and abusive or poor quality of interpersonal care. Hence, women's dissatisfaction with childbirth services was cited as being responsible for under-utilization of facilitybased childbirth services in Ethiopia [2,11].

To date, there have been very few facility-based studies focused on mother's satisfaction towards skilled delivery services in Ethiopia. Those studies also constituted only a small aspect of variables and therefore impossible to provide information on key variables that are likely to influence mother's satisfaction on delivery service and none had specifically assessed their future intention to use delivery services again. Therefore, this study was designed to assess satisfaction towards skilled delivery services among mothers who gave birth at government health facilities, Jimma town, South-West Ethiopia, 2014.

\section{Methods}

\section{Study area and period}

The study was conducted at Jimma town government health facilities from March 5-May 10/2014. Jimma town is located $357 \mathrm{~km}$ Southwest of Addis Ababa with a total projected population of 151,010. The town has five government health facilities (Jimma University Specialized Hospital, Shenen Gibe hospital, Jimma health centers, Higher 2 health centers and Mendera Kochi health centers). JUSH serves for a catchment population estimated to be 1.2 million people and the annual expected deliveries were 14400. In the 2013 fiscal year, this specialized hospital had conducted 4176 deliveries with an average monthly delivery of 346 . Shenen Gibe hospital and the health centers serve for 185940 people with 6240 annual expected deliveries. In the
2013 fiscal year, Shenen Gibe hospital, Jimma HC, Higher 2 HC, and Mendera Kochi HC had conducted 446, 252, 228, and 122 deliveries with an average monthly delivery service of $37,21,19,11$ respectively (Jimma town health office and JUSH).

\section{Study design}

A cross-sectional study with both quantitative and qualitative methods of data collection was employed. The qualitative data were used to support the findings of quantitative results.

\section{Source and study population}

All postnatal mothers who were visiting Jimma town government health facilities for delivery service during the study period were the source populations. Sampled mothers who gave birth at those health facilities during the study period were the study population for quantitative data. Purposively selected postnatal mothers during the study period were included for an in-depth interview. Mothers were selected on basis of previous facility-based birth experience and based on the need of the study.

\section{Inclusion and exclusion criteria}

All postnatal mothers who gave birth at Jimma town government health facilities were included. Those mothers who were critically sick to be interviewed and postnatal mothers with stillbirths or neonatal deaths at present pregnancy were excluded on the basis that women with stillbirth might give a misrepresented view and might affect the results of the study of this nature.

\section{Sample size}

The sample size was determined using single population proportion formula with the following assumptions: $\mathrm{P}=$ proportion of satisfied mothers with delivery care service as $61.9 \%(\mathrm{p}=0.619)$ [12], $\mathrm{Z} \alpha / 2=$ $95 \%$ confidence interval, $d=$ margin of error $(d=4 \%)$. With the above assumptions, the formula yields 567. Since the number of average expected deliveries conducted in health facilities within study period was less than 10,000, correction formula was used as follow: $\mathrm{nc}=\mathrm{n} /$ $(1+n / \otimes) n c=567 /(1+567 / 868) n c=344$. Adding non-responses rate of $10 \%$, a total sample size of 378 mothers were selected. From reviewing the annual document of skilled delivery services in the 2013 fiscal year, the average expected deliveries during the study period (two months) were 692,74,42,38 and 22 in JUSH, Shenen Gibe hospital, Higher 2 HC, Jimma HC and Mendera Kochi HC, respectively. Hence, the total expected deliveries during data collection period were 868 . The total sample was allocated proportionally to each health facilities (two hospital and three health center). Thus, sample size for JUSH, Shenen Gibe hospital, Higher $2 \mathrm{HC}$, Jimma HC and Mendera Kochi HC were $298,36,17,16$ and 11, respectively. For the in-depth interview, 22 postnatal mothers were involved.

\section{Sampling technique}

The sampling interval for each health facilities $(\mathrm{K})$ was determined by dividing the number of average expected deliveries during the study period by the sample size of each health facilities. Thus, $\mathrm{K}=2$ for each health facilities. Study participants were selected systematically. The first mother was selected by lottery method from their order of discharge. Every other mother just at the exit of the health facility was selected till the sample was fulfilled. For the in-depth interview, 
postnatal mothers who were not included in the quantitative study were selected purposively on basis of women who had given birth in health facility previously and based on the need of the study.

\section{Data collection methods}

Data were collected using structured, interviewer-administered questionnaires which were adapted from Labour and delivery satisfaction index questionnaires, birth satisfaction scale questionnaire, Jipi's postnatal satisfaction with nursing care questionnaires [13-17]. The questionnaires were comprised of 44 items. Level of satisfaction was indicated by selecting responses ranging from very dissatisfied $=1$, dissatisfied $=2$, neutral $=3$, satisfied $=4$, and very satisfied $=5$. These contextually adapted questionnaires were pre-tested in $5 \%$ of samples in JUSH before the actual data collection period and some questionnaires were changed. The satisfaction scale questionnaires had a reliability score ranging from 0.735 to 0.863 as shown below (Table $1)$.

\begin{tabular}{|l|l|}
\hline Scale & Cronbach's alpha value \\
\hline Organizational aspect questions & 0.735 \\
\hline Technical aspect questions & 0.862 \\
\hline Overall satisfaction scale questioners & 0.838 \\
\hline
\end{tabular}

Table 1: Reliability score for a measure of the satisfaction scale.

The questionnaires were translated into two local languages (Amharic and Affaan Oromo) by three independent translators and then back to English to make sure the questionnaires were clear and to check for consistency. Five female nurses who were not working in the study sites were recruited for data collection. Data collectors and supervisors were trained for two days before the actual data collection. Data collectors were those who were not working in the maternity ward to minimize interviewer bias. Qualitative data were collected through in-depth interview guide. The in-depth interview guide had probing questions on areas of skilled delivery service satisfaction (client-care provider interaction, information provision, respect to client and health facility-related factors) to collect their suggestions regarding on satisfaction/dissatisfaction. All information's were taperecorded and field notes were taken and transcribed to texts immediately. Data were collected until saturation points of ideas had been reached. Both data were collected in the separate room in having women feel reassured that they could speak freely about satisfaction.

\section{Data processing and analysis}

Questionnaires were checked for completeness, entered into Epidata version 3.1, and then exported to SPSS version 20.0 for further analysis. Data were edited and cleaned for inconsistencies. Descriptive statistics were computed and logistic regression analysis was applied to see the association between dependent and independent variables. The variables with $\mathrm{p}<0.05$ in multiple logistic regression model were considered as significant predictors of satisfaction towards delivery service. The odds ratio was used to determine the strength of association between selected variables. Additionally, to measure overall satisfaction level indirectly respondents were asked 'how likely are you to recommend this facility for delivery care to your family or friends?' and 'how likely are you to deliver in this same facility again?' The response categories were 'very likely', 'somewhat likely', neutral 'somewhat unlikely' and 'very unlikely'. During analysis, the responses of 'very likely' and 'somewhat likely' were classified as 'likely' and responses of 'very unlikely' and 'unlikely' were classified as 'unlikely'. The response "unlikely" was considered as "dissatisfied" because unlikely responses were believed to reflect some reservation about the service received) [14].

For qualitative data, the in-depth interview was conducted with local languages and was transcribed and then translated into English. Next completed transcription was compared with handwritten notes to fill the gaps. The data were coded as "R1"for the first interviewed mother, R2, R3....R22 for the final interviewed mother and grouped based on thematic areas (two thematic areas-health facility related and care-provider related). Concepts were extracted from themes and presented in narratives and used to support quantitative results.

\section{Operational definitions}

Satisfaction: Meeting perceived needs and expectations of mothers in relation to process and health institution aspects of delivery service as measured by 5 point Likert scale questions.

Cut off point for satisfaction: Since each item had 5 points Likert scale which ranges between 1 and 5 ; the scores were calculated by summing the answers to all items. Cut off point was calculated using the demarcation threshold formula: \{(total highest score-total lowest score) $/ 2\}+$ Total lowest score $[18,19]$.

Mothers overall satisfaction level: By summing up the response of 19 satisfaction questions those who were satisfied above the cut point were categorized as satisfied and those who were satisfied less than cut point were categorized as dissatisfied $[18,19]$.

Waiting time: Perceived time interval from arrival of the mother at the hospital/health center until first registered. The actual waiting time this is less than $30 \mathrm{~min}$.

\section{Ethical Consideration}

The ethical clearance was obtained from the institutional review board of collage of public health and medical sciences, Jimma University. A formal letter was submitted to each respective health facilities. Written consent was obtained from the study participants. To ensure privacy and confidentiality, the exit interview was conducted where questions and answers could not be overheard. Identifying information including name was not recorded in questionnaires.

\section{Results}

A total of 366 postnatal mothers were enrolled in the study with the response rate of $96.8 \%$; of which $78.8 \%$ were from JUSH, $9.3 \%$ from Shenen Gibe hospital, 4.4\% from Higher 2 HC, 4.4\% from Jimma HC and 3.0\% from Mendera Kochi health center.

\section{Socio-demographic characteristics}

The average age of postnatal mothers was $25.45 \pm 4.9$ years. Two hundred thirty-three (64\%) mothers came from urban and $90.4 \%$ were married. Regarding ethnic and religious distribution, the dominant ethnicities were Oromo (68.1\%) while the dominant religion was Muslim (51.1\%). One hundred ninety-eight (54.1\%) mothers were housewives and $37.1 \%$ of mothers attended primary education. More than half of mothers had an average family monthly income between 500-1500 Ethiopian birr (Table 2). 
Citation: Gonie A, Tebeje B, Sinaga M (2018) Satisfaction towards Skilled Delivery Services and Associated Factors among Mothers who Gave Birth at Government Health Facilities, Jimma Town, Ethiopia. Clinics Mother Child Health 15: 302. doi:10.4172/2090-7214.1000302

Page 4 of 7

\begin{tabular}{|c|c|c|c|}
\hline \multicolumn{2}{|c|}{ Socio-demographic variable } & \multirow{2}{*}{\begin{tabular}{|l}
$\begin{array}{l}\text { Number } \\
(\mathrm{n}=366)\end{array}$ \\
69
\end{tabular}} & \multirow{2}{*}{$\begin{array}{l}\text { Presen } \\
18.9\end{array}$} \\
\hline Age & $\leq 20$ & & \\
\hline & $21-34$ & 250 & 68.3 \\
\hline & $35-49$ & 47 & 12.8 \\
\hline \multirow[t]{3}{*}{ Marital status } & Married & 331 & 90.4 \\
\hline & single & 19 & 5.2 \\
\hline & Divorced/widowed & 16 & 4.4 \\
\hline \multirow[t]{4}{*}{ Religion } & Muslim & 187 & 51.1 \\
\hline & Orthodox & 107 & 29.2 \\
\hline & Protestant & 63 & 17.2 \\
\hline & Others & 9 & 2.5 \\
\hline \multirow[t]{4}{*}{ Ethnicity } & Oromo & 249 & 68.1 \\
\hline & Amara & 39 & 18.1 \\
\hline & Gurage & 29 & 7.9 \\
\hline & $\begin{array}{l}\text { Others } \\
\text { Dauro) }\end{array}$ & 45 & 12.3 \\
\hline \multirow[t]{6}{*}{ Occupation } & Housewife & 97 & 54.1 \\
\hline & Marchant & 42 & 11.5 \\
\hline & Government employee & 38 & 10.4 \\
\hline & Private employee & 38 & 10.4 \\
\hline & Farmer & 33 & 8.8 \\
\hline & Others & 17 & 4.6 \\
\hline \multirow[t]{4}{*}{ Educational level } & No formal education & 113 & 30.9 \\
\hline & Primary education & 136 & 37.7 \\
\hline & High school education & 75 & 20.5 \\
\hline & College education & 42 & 11.5 \\
\hline \multirow[t]{2}{*}{ Residence } & Urban & 234 & 63.9 \\
\hline & Rural & 132 & 36.1 \\
\hline \multirow{3}{*}{$\begin{array}{l}\text { Monthly family } \\
\text { income in cash } \\
\text { (approximately) }\end{array}$} & $<500$ & 126 & 34.3 \\
\hline & $500-1500$ & 206 & 56.4 \\
\hline & $>1500$ & 34 & 9.3 \\
\hline
\end{tabular}

section. Two hundred sixty mothers (71.0\%) stayed on labour less than 12 hours and about three-fourths $(76.1 \%)$ of mothers were normal immediately after delivery (Table 3).

\begin{tabular}{|c|c|c|c|}
\hline \multicolumn{2}{|l|}{ Obstetric characteristics } & \multirow{2}{*}{$\begin{array}{l}\begin{array}{l}\text { Number } \\
(n=366)\end{array} \\
141\end{array}$} & \multirow{2}{*}{$\begin{array}{l}\begin{array}{l}\text { Prese } \\
\text { nt }\end{array} \\
38.3 \\
\end{array}$} \\
\hline Parity & One & & \\
\hline & Two-five & 182 & 49.3 \\
\hline & More than five & 42 & 11.4 \\
\hline \multirow[t]{2}{*}{ Status of pregnancy } & Wanted & 321 & 87.7 \\
\hline & Unwanted & 44 & 12.3 \\
\hline \multirow[t]{4}{*}{ ANC visits } & One & 20 & 5.5 \\
\hline & Two & 35 & 9.5 \\
\hline & Three & 126 & 34.5 \\
\hline & Four and more & 185 & 50.5 \\
\hline \multirow{2}{*}{$\begin{array}{l}\text { Reason for health facility } \\
\text { visit }\end{array}$} & Planned delivery & 163 & 44.5 \\
\hline & Referral delivery & 203 & 55.5 \\
\hline \multirow[t]{2}{*}{ Mode of delivery } & $\begin{array}{l}\text { Assisted } \\
\text { delivery }\end{array}$ & 275 & 75.3 \\
\hline & Caesarian section & 91 & 24.7 \\
\hline \multirow[t]{3}{*}{ Duration of last delivery } & $<12$ & 260 & 71.0 \\
\hline & $12-24$ & 89 & 24.3 \\
\hline & $>24$ & 17 & 4.6 \\
\hline \multirow{2}{*}{$\begin{array}{l}\text { Maternal condition after } \\
\text { delivery }\end{array}$} & Normal & 278 & 76.1 \\
\hline & With complication & 87 & 23.9 \\
\hline
\end{tabular}

Table 3: Obstetric characteristics of mothers who gave birth at Jimma town health facilities, Ethiopia, 2014.

In this study, three hundred four $(83.1 \%)$ of mothers admitted in the ward within $30 \mathrm{~min}$. Almost three fourth (74.6\%) of mothers obtained free delivery service. More than half of mothers (58.2\%) perceived that the toilet was not cleaned and almost three-fourths of mothers (77.6\%) responded that the delivery room was not cleaned. Regarding care provider interaction, two hundred sixty-six $(72.7 \%)$ of mothers responded that staffs showed politeness, courtesy, and respect to mothers. The majority, $(68.6 \%)$, of mothers perceived that their confidentiality was assured and two third (61.2\%) of mothers responded that their privacy was maintained during the examination (Table 4).

Table 2: Socio-demographic characteristics of mothers who gave birth at Jimma town Health Facilities, Ethiopia, 2014.

\section{Obstetrics characteristics of postnatal mothers}

Among the total participants, nearly half of them (49.3\%) had 2 to 5 deliveries. Three hundred twenty-one (87.7\%) respondents agreed that their current delivery was wanted. Half $(50.5 \%)$ of mothers had attended four and more ANC visits. More than half of mothers (55.5\%) had visited the health facilities for referral delivery from other health facilities. Around a quarter (24.7\%) of mothers gave birth by caesarean

\begin{tabular}{|l|l|l|l|}
\hline \multicolumn{2}{|l|}{ Variables } & Number (n=366) & Present \\
\hline Waiting time to be admitted & $<30 \mathrm{~min}$ & 304 & 83.1 \\
\cline { 2 - 4 } & $>30 \mathrm{~min}$ & 62 & 16.9 \\
\hline Payment status & Free & 273 & 74.6 \\
\cline { 2 - 4 } & Paid & 93 & 25.4 \\
\hline Waiting room cleanness & Yes & 264 & 72.6 \\
\hline
\end{tabular}




\begin{tabular}{|l|l|l|l|}
\hline & No & 102 & 27.4 \\
\hline $\begin{array}{l}\text { Satisfied with the cleanness of } \\
\text { toilets? }\end{array}$ & Yes & 213 & 58.2 \\
\cline { 2 - 4 } & No & 153 & 41.8 \\
\hline $\begin{array}{l}\text { Availability of staffs at any time } \\
\text { you need? }\end{array}$ & Yes & 254 & 69.4 \\
\cline { 2 - 4 } & No & 112 & 30.6 \\
\hline Has the confidentiality assured & Yes & 251 & 68.6 \\
\cline { 2 - 4 } & No & 115 & 31.4 \\
\hline $\begin{array}{l}\text { Has privacy maintained during } \\
\text { the examination? }\end{array}$ & Yes & 224 & 61.2 \\
\cline { 2 - 4 } $\begin{array}{l}\text { Have staffs shown politeness, } \\
\text { courtesy, respect (care provider } \\
\text { interaction)? }\end{array}$ & Yes & 142 & 38.8 \\
\hline & No & 100 & 72.7 \\
\hline $\begin{array}{l}\text { Obtained information and } \\
\text { education service } \\
\text { planning, breastfeeding, baby } \\
\text { care) }\end{array}$ & Yes & 248 & 27.3 \\
\cline { 2 - 4 } & No & 118 & 67.8 \\
\hline
\end{tabular}

Table 4: Mother's response to the different dimensions of delivery services at Jimma town Health Facilities, Ethiopia, 2014.

\section{Level of mother's satisfaction on delivery service}

In this study, two hundred eighty-eight (78.7\%) of mothers were satisfied and the rest $21.1 \%$ were dissatisfied with skilled delivery services. Based on the component-wise level of satisfaction, $83.5 \%$ of mothers were satisfied with the process aspect of delivery services and $68.1 \%$ of mothers were satisfied with institutional aspect of delivery service. Meanwhile, dissatisfaction was higher in institutional aspect of delivery service $31.9 \%$ (Figure 1).

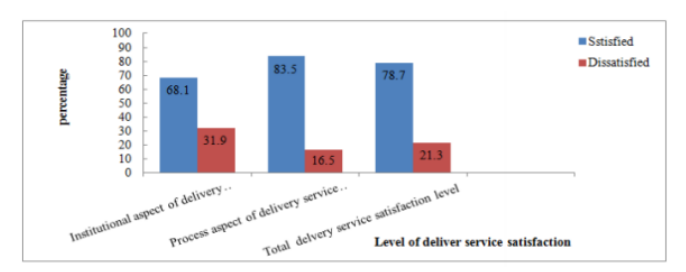

Figure 1: Component wise level of delivery service satisfaction among mothers who gave birth at Jimma town Health Facilities, Ethiopia, 2014.

In line with quantitative results, the interviews also showed that many mothers were happy, while some were unhappy as the quote below illustrates:

"...I would be totally lost if they weren't here, they have really helped me" (R7 JUSH).

Another interviewed mother from Shenen Gibe Hospital said that:

'...I think staffs were just really helpful, and I could get what I want during my stay" (R3 Shenen Gibe Hospital).

However, few of the interviewed mothers reported that there was still a problem in respecting clients. One participant said;
"...Majority of staff members had good respect to mothers, but some of the staffs show unexpected behavior and even insult our relatives and were still unethical...."(R17 JUSH)

Majority of the interviewed mothers from JUSH shared the idea that they were dissatisfied with the cleanness of toilets. One of the interviewed mother said that:

"..I was not happy with toilets because there was no water, was not tidy" (R2 JUSH).

Another interviewed mother from Higher $2 \mathrm{HC}$ said that;

"...There was nothing bad but for me, I think the toilet was far away and not clean..." (R2 higher $2 \mathrm{HC}$ ).

Of all interviewed, majority of the respondents complained that the way privacy was maintained. One mother reported that:

"...I didn't expect to have such type of service, no one was following delivery procedures until the end, they were frequently changed, I think they were students and did not look after me, and that was just not good..." (R12 JUSH).

\section{Another interviewed also said that:}

"..I was not happy the way privacy was maintained during examinations because many students were around $245 \mathrm{me}$, so I did not feel comfort". I have been made frequent vaginal examination..." (R15 JUSH).

Mothers were asked about a sort of information they felt and they needed during discharge from health facility. For some mothers, it was information that would help them to develop their confidence in basic practical aspects of the care of their baby such as nappy changing, BF and bathing the baby. However, for few mothers a range of insufficient information was raised, as illustrated in the following:

"...Health professionals told me how to breastfeed, but I have not told how often I did breastfeed and how often I did change the baby nappy?".

To measure satisfaction of mothers indirectly, questions exploring the willingness of mothers to recommend the health facility to family or friends, and delivered in this same health facility again were asked. From these questions, $86.9 \%$ of mothers responded that they were likely to recommend this health facility to their family or friends. Regarding delivering in this same health facility again, $89.4 \%$ of mothers responded that they were likely to deliver in this same facility again (Figure 2).

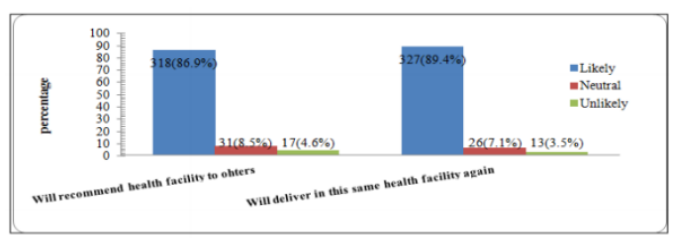

Figure 2: The response of mothers (will recommend/ delivered again in the same health facility) who gave birth at Jimma town Health Facilities, Ethiopia, 2014. 


\section{Factors associated with delivery service satisfaction}

Multiple logistic regression analysis was conducted to control confounding. The results from multiple logistic regression model showed that five influential predictors of delivery service satisfaction out of thirteen reported from the crude analysis. These were the reason for health facility visit (planned delivery), payment status (free delivery service), cleanness of the toilets (cleaned), privacy maintained by the health staffs (privacy was maintained) and being treated with respect (yes) (Table 5).

\begin{tabular}{|c|c|c|c|c|c|c|}
\hline \multicolumn{2}{|l|}{ Variables } & \multirow{3}{*}{$\begin{array}{l}\begin{array}{l}\text { Satisfied } \mathbf{N} \\
(\%)\end{array} \\
133(90.3)\end{array}$} & \multirow{3}{*}{$\begin{array}{l}\text { COR } \\
4.026\end{array}$} & \multirow{3}{*}{$\begin{array}{l}\text { AOR } \\
2.500\end{array}$} & \multicolumn{2}{|l|}{$95 \% \mathrm{Cl}$} \\
\hline & & & & & Lower & Upper \\
\hline \multirow{2}{*}{$\begin{array}{l}\text { Reason for } \\
\text { health facility } \\
\text { visit }\end{array}$} & $\begin{array}{l}\text { Planned } \\
\text { delivery }\end{array}$ & & & & 1.118 & 5.588 \\
\hline & $\begin{array}{l}\text { Referral } \\
\text { delivery }\end{array}$ & $155(68.0)$ & & 1 & & \\
\hline \multirow[t]{2}{*}{ Payment status } & Free & $230(84.2)$ & 3.289 & 2.864 & 1.273 & 6.440 \\
\hline & Paid & $58(57.7)$ & & 1 & & \\
\hline \multirow{2}{*}{$\begin{array}{l}\text { Satisfied with } \\
\text { the cleanness } \\
\text { of toilets? }\end{array}$} & Yes & $166(88.1)$ & 4.030 & 2.014 & 1.016 & 3.793 \\
\hline & No & $122(67.8)$ & & 1 & & \\
\hline \multirow{2}{*}{$\begin{array}{l}\text { Being treated } \\
\text { with respect }\end{array}$} & Yes & $221(85.9)$ & 3.787 & 1.670 & 1.126 & 6.845 \\
\hline & No & $67(61.5)$ & & 1 & & \\
\hline \multirow{2}{*}{$\begin{array}{l}\text { Did the privacy } \\
\text { maintained } \\
\text { during the } \\
\text { examination? }\end{array}$} & Yes & $182(86.7)$ & 3.137 & 1.471 & 1.278 & 9.463 \\
\hline & No & $106(67.9)$ & & 1 & & \\
\hline
\end{tabular}

Table 5: Multivariate analysis of predictor variables of mother's satisfaction at Jimma town Health Facilities, Ethiopia, 2014.

The regression analysis indicated that mothers who had planned delivery were 2.5 times more likely to be satisfied than those referral delivery cases (AOR 2.5and 95\% CI=1.2-5.6). Mothers who obtained free delivery service were 2.9 times more likely to be satisfied than mothers who paid for the services (AOR=2.9 and 95\% $\mathrm{CI}=1.3-6.4$ ). It was also observed that mothers satisfaction were affected by cleanness of toilets i.e. mothers who perceived that the toilet was cleaned were 2 times more likely to be satisfied than their counterparts ( $\mathrm{AOR}=2.0$ and 95\% CI=1.01-3.8). Moreover, mothers who felt being treated with respect were 1.7 times more likely to be satisfied than mothers who did not be respected $(\mathrm{AOR}=1.7$ and $95 \% \mathrm{CI}=1.1-6.8)$ and mothers who perceived that their privacy was maintained by health staffs were 1.5 times more likely to be satisfied than their counterparts.

\section{Discussions}

The overall proportion of mothers who were satisfied with the delivery service in this study was $78.7 \%$. This percentage was lower compared to other studies in developing countries- Malawi (97.3\%) [20], and it was comparable with a study in Wolaita zone, Southern Ethiopia (82.4\%) [21], but it was greater than a study in Sri Lanka $48 \%$ [22], Nairobi Kenya (56\%) [14], Sweden (67\%) [23], South Africa (50.6) [24] and study done in Amhara region referral hospitalsEthiopia (61.9\%) [12]. The difference could be due to the subjective nature of satisfaction, and/or study period difference due to the increased in expectation of mothers to the service they are going to receive with rapid advancement in technology and it might also be a real difference in quality delivery service provided or the type of health facilities in different settings. The underlying justifications for higher mothers' satisfaction with delivery service in Ethiopia might be the focus of attention for the government of Ethiopia to reduce maternal mortality.

The study also showed that $86.9 \%$ of mothers were likely to recommend this health facility for delivery service to their family or friends and $89.4 \%$ of mothers were likely to deliver in this same facility again. This percentage was higher than study conducted in Kenya in which $60 \%$ of women recommend the facility to others or to deliver there again [14] and in Amhara region referral hospitals in which $69.1 \%$ of mothers were very likely to recommend the hospital where they delivered to others and $68.8 \%$ of delivering mothers were likely to deliver in the hospital where they delivered again [12]. This difference suggested that the health facilities were providing an acceptable quality of delivery service and there was a substantial improvement.

In this study, there was no relationship between sociodemographic variables and overall level satisfaction. This could be due to the fact that most sociodemographic variables did not affect the overall level of satisfaction; hence they did not influence the mother's expectations. However, the reason for health facility visit, payment status, cleanness of the toilets, privacy maintained by the health staff and being treated with respect were predictors of satisfaction towards delivery service.

In this study, mothers who had planned delivery were 2.5 times more likely to be satisfied than those referral delivery cases. Mothers who had planned delivery might have high faith on the service as they were received during their last pregnancy and this contributed to their satisfaction with care. On the other hand, if mothers with referral delivery expected pleasant delivery service but had an unpleasant one, then they might be dissatisfied.

In this study, mothers who obtained free delivery service were 2.9 times more likely to be satisfied than mothers who paid for delivery service. This result was similar with the study done in India; in which the cost of the service was one of the seven key determinants of delivery care [7] and Amhara region referral hospitals [12]. This might be mother's expectation of cost of delivery service and the application of cost exempted service of delivery services.

A study done in South Africa, cleanliness of the ward and condition of toilets were areas requiring serious attention needing most urgent improvements [24]. In the current study, mothers who perceived that the toilet was cleaned were 2 times more likely to be satisfied than their counterparts. This reflected there was poor cleanness of toilets which should be improved. Moreover, mothers who felt being treated with respect were 1.7 times more likely to be satisfied than mothers who did not be respected. This was consistent with studies conducted in United States military hospitals [25], Ghana [26] and Nairobi Kenya [14]. Thus, this further strengthened the argument that interpersonal relationships including being treated with respect constituted an essential determinant of mother's satisfaction. If a positive caregiver attitude was attained, mothers would find the health facility safe enough to deliver again at the health facility. Similarly, the same result was obtained from the in-depth interview in which there were still problems with courtesy and respect by some health staffs [27].

During providing delivery services, respect for privacy was one of the aspects in which mothers were most satisfied. In this study, mothers who perceived that their privacy was maintained by health 
staffs were 1.5 times more likely to be satisfied than their counterparts. This agreed with studies done in Sri Lanka [22] and Amhara region referral hospitals in which the absence of privacy was a means for dissatisfaction [12]. This reflected there was privacy breach which made mothers be dissatisfied. If the health facilities were safe enough because of inadequate privacy during the physical examination, this led to mothers might not use the health facilities in the future.

\section{Conclusions}

In this study, more than three-fourths of mothers were satisfied towards skilled delivery services. Dissatisfaction was higher in the organizational aspect of delivery service than the technical aspects. This study also revealed predictors of satisfaction with skilled delivery services including; planned delivery, free delivery service, perceived cleanness of toilets, perceived presence of privacy maintained by the health staff and empathetic interactions of staffs. Therefore, those health facilities should use screens and curtains where more than one woman was delivering in the same room. The health facilities also should enhance cleanliness of toilets to improve the environment of the health facilities. The health facilities administrators should check curb irregularities in supplies of medications/delivery materials associated with deliveries to avoid informal payments. Thus, full application of cost exempted service should be applied for mothers coming for delivery.

\section{References}

1. WHO (2014) Trends in maternal mortality: 1990 to 2013. Estimates by WHO, UNICEF, UNFPA, The World Bank and the United Nations Population Division.Geneva, Switzerland.WHO 1-56.

2. Yohannes B, Tarekegn M, Paulos W (2013) Mothers " Utilization Of Antenatal Care And Their Satisfaction With Delivery Services In Selected Public Health Facilities Of Wolaita Zone, Southern Ethiopia. Int J Sci Tech Res 2: 74-85.

3. Das P, Basu M, Tikadar T, Biswas GC, Mridha PPR (2010) Client satisfaction on maternal and child health services in rural Bengal. Indian J Community Med 478-482.

4. WHO (2004) World Health Organization. Making pregnancy safer》: the

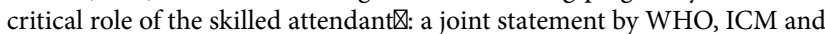
FIGO. Geneva,Swithrland WHO.

5. Donabedian A (1988) The quality of care: How can it be assessed? JAMA 260: $1743-1748$.

6. Redshaw M (2008) Women as Consumers of Maternity Care囚: Measuring Satisfaction or Dissatisfaction囚? Birth 35: 73-76.

7. Aradhana Srivastava A, Avan BI, Rajbangshi PR, Bhattacharyya S (2012) Women's Perceptions of Quality and Satisfaction with Maternal Health Services.state of Jharkhand, India, US. Agency for International Development funded MCH-STAR Initiative, Public Health Foundation of India.

8. WHO (2012) Trends in maternal mortality: 1990 to 2010 WHO, UNICEF, UNFPA and the World Bank estimates.

9. WHO (2010) Federal Democratic Republic of Ethiopia Ministry of Health: Health Sector Development Programme IV 2010/11-2014/15.

10. WHO, Inter-Agency Group Ethiopia (2014) Maternal mortality in 1990-2013. WHO, UNICE, UNFPA, The World Bank, and United
Nations Population Division Maternal Mortality Estimation InterAgency Group Ethiopia.

11. Kebede B, Gebeyehu A, Andargie G (2013) Use of previous maternal health services has a limited role in reattendance for skilled institutional delivery: cross-sectional survey in Northwest Ethiopia. Int J Womens Health 79-85.

12. Tayelgn A, Zegeye DT, Kebede Y (2011) Mothers' satisfaction with referral hospital delivery service in Amhara Region, Ethiopia. BMC Pregnancy Childbirth 11: 78 .

13. Varghese J, Rajagopal K (2012) A study to evaluate the level of satisfaction perceived by postnatal mothers following nursing care in postnatal wards as expressed by themselves: pilot study. 2: 101-112.

14. Bazant ES, Koenig M (2009) Women's satisfaction with delivery care in Nairobi's informal settlements. Int J Qual Health Care 21: 79-86.

15. Martin CH, Fleming V (2011) The birth satisfaction scale. Int J Qual Health Care Ass 24: 124-135.

16. Janssen PA, Dennis CL, Reime B (2006) Development and Psychometric Testing of the Care in Obstetrics $\bigotimes$ : Measure For Testing Satisfaction (COMFORTS) Scale. Res Nurs Health 29: 51-60.

17. Moudi Z, Tabatabaeii MG, Saeedi ZA, Vedadhir AA, Baheiraei A, et al. (2012) Measuring women's expectations of childbirth care services in a developing country: development and validation of scales. J Public Health 20: $541-548$

18. Fantaye C, Fessahaye A, Desta W (2014) Satisfaction with focused antenatal care service and associated factors among pregnant women attending focused antenatal care at health centers in Jimma town , Jimma zone, South West Ethiopia. BMC Res Notes 7: 164.

19. Mindaye T, Taye B (2012) Patients satisfaction with laboratory services at antiretroviral therapy clinics in public hospitals, Addis Ababa, Ethiopia. BMC Res Notes. 5: 184.

20. Changole J, Taulo F, Makanani B, Nkanaunena K, Taulo F, et al. (2010) Patients' satisfaction with reproductive health services at Gogo Chatinkha Maternity Unit, Queen Elizabeth Central Hospital, Blantyre, Malawi. Malawi Med J 22: 5-9.

21. Yohannes B, Tarekegn M, Paulos W (2013) Mothers "Utilization of Antenatal Care And Their Satisfaction With Delivery Services In Selected Public Health Facilities of Wolaita Zone, Southern Ethiopia: Int J Sci Technol Res 2 .

22. Senarath U, Fernando DN, Rodrigo I (2006) Factors determining client satisfaction with hospital-based perinatal care in Sri Lanka. Trop Med Int Health 11: 1442-1451.

23. Rudman A, El-khouri B, Waldenstro U (2007) Women's satisfaction with intrapartum care-a pattern approach, Stockholm, Sweden. J Adv Nurs 59: 474-487.

24. Lumadi TG, Buch E (2011) Patients' satisfaction with midwifery services at a regional hospital and its referring clinics in the limpopo province of South Africa. Africa J Nurs Midwifery 13: 14-28.

25. Harriott EM, Williams TV, Peterson MR (2005) Childbearing in US Military Hospitals: Dimensions of Care Affecting Women's Perceptions of Quality and Satisfaction Birth 32: 4-10.

26. Avortri GS, Beke A, Abekah-Nkrumah G (2011) Predictors of satisfaction with child birth services in public hospitals in Ghana. Int J Health Care Qual Assur 24: 223-237.

27. Abaynew Y, Deribew A , Deribe K (2011) Factors associated with late presentation to HIV/AIDS care in South Wollo ZoneEthiopia区: a casecontrol study. AIDS Res Ther 8: 8 . 